\title{
Registration bias in a clinical quality register
}

\section{(ㄷ)(i)}

\author{
Authors \\ Institutions \\ 1 Telemark Hospital, Skien, Norway \\ 2 University of Oslo, Institute of Clinical Medicine, Oslo, \\ Norway \\ 3 Oslo University Hospital, Oslo, Norway \\ 4 University of Oslo, Institute of Health and Society, Oslo, \\ Norway \\ 5 Frontier Science Boston, Boston, Massachusetts, \\ United States \\ 6 Telemark Hospital Notodden, Notodden, Norway \\ 7 Drammen Hospital, Drammen, Norway \\ 8 Sørlandet Hospital, Kristiansand, Norway \\ 9 Telemark Hospital Kragerø, Kragerø, Norway \\ 10 Østfold Hospital, Grålum, Norway \\ 11 Vestfold Hospital, Tønsberg, Norway
}

Geir Hoff ${ }^{1,2}$, Thomas de Lange ${ }^{2,3}$, Michael Bretthauer ${ }^{4,5}$, Stein Dahler ${ }^{6}$, Fred-Arne Halvorsen ${ }^{7}$, Gert Huppertz-Hauss ${ }^{1}$, Ole Høie $^{8}$, Øystein Kjellevold ${ }^{9}$, Volker Mortiz ${ }^{1}$, Per Sandvei ${ }^{10}$, Birgitte Seip ${ }^{11}$, Øyvind Holme ${ }^{8}$

submitted 11.5.2018

accepted after revision $\quad 2.10 .2018$

\section{Bibliography \\ DOI https://doi.org/10.1055/a-0806-7006 | \\ Endoscopy International Open 2019; 07: E90-E98 \\ (c) Georg Thieme Verlag KG Stuttgart · New York \\ ISSN 2364-3722}

Corresponding author

Geir Hoff, Telemark Hospital - Dept. of Research,

Ulefossveien 55 Skien 3710, Norway

Fax: +35004132

hofg@online.no

Supplementary data

Online content viewable at:

https://doi.org/10.1055/a-0806-7006

\section{ABSTRACT}

Background and aims The quality of medical quality registers is poorly defined and lack of trust in data due to low completeness may be a major barrier against their use in quality improvement interventions. The aim of the current observational study was to explore how selective reporting may influence adverse events registered in the Norwegian quality register for colonoscopy (Gastronet).

Materials and methods Gastronet's database includes data provided by endoscopists, nurses and patients. All outpatient colonoscopies reported to Gastronet in 2015 were included and compared to the total number of colonoscopies performed in Norway as retrieved from the National Patient Registry. Hospitals were categorized into four groups according to reporting completeness $<50 \%$, $50 \%$ to $69 \%, 70 \%$ to $89 \%$ and $\geq 90 \%$. The number of recorded adverse events (AEs) and procedure time were analyzed. Multivariate logistic regression models were fitted to explore independent factors for selection bias.

Results A total of 22,364 colonoscopies were reported to the National Patient Register of which 15,855 (71\%) were registered in Gastronet. Feedback was received from 11,079 patients (50\%). The frequency of AEs increased from $0.6 \%$ in completeness group $<50 \%$ to $1.6 \%$ in completeness group $\geq 90 \%(P<0.001)$. Long colonoscopy procedure time was associated with low reporting completeness. Patient feedback was associated with older age, cecal intubation success and sedation-free colonoscopy.

Conclusion Incomplete registration in a colonoscopy quality register is associated with underreporting of AEs. Longer procedure time, a surrogate marker for time constraint, is associated with low completeness.

\section{Introduction}

Quality assurance (QA) is a prerequisite for modern health care services, but we have limited knowledge to define the quality of quality registers. Reporting may be selective, causing selection bias in QA databases. When this happens to reporting of impor- tant outcomes like adverse events (AEs), it may seriously jeopardize the validity of $Q A$ registers. Not being sufficiently aware of their possible shortcomings, QA registers may do unwarranted harm to the health service [1]. Also, underreporting of substandard performance may create "feel-good" registers unable to reveal the true need for quality improvement. 
There is no standard to define a reliable quality register. Ninety percent may be arbitrarily described as good and less than $70 \%$ to $80 \%$ as inadequate [2-3]. Adequate completeness may also depend on whether we are dealing with high-frequency events like the proportion of patients sedated for colonoscopy (quality of process) and the proportion of colonoscopies reaching the cecum (quality of results) or low-frequency $A E$. A register with $90 \%$ completeness may be of little help if disproportionately many low-frequency AEs occur among the $10 \%$ not reported. It is known from the software industry that a linear increase in coverage or completeness may result in an exponential increase in errors detected [4]. Thus, a high degree of register completeness may not by itself prevent selection bias of clinical importance.

The requirement for patients' written consent and underreporting from doctors and hospital staff are sources of bias with unknown effects on the validity of QA registers. "Limited resources" and "time squeeze" have been identified as major reasons for not reporting to quality registers [5]. In the current study, we have used data on colonoscopies from the Norwegian national quality register Gastronet to demonstrate consent-dependent bias and explore the hypothesis of endoscopist timesqueeze-dependent underreporting to estimate what possible effect this may have on registration of AEs.

\section{Materials and methods}

Gastronet is one of 54 national medical quality registers in Norway. It includes registration of colonoscopies and endoscopic retrograde cholangiopancreatography examinations. The current study comprised colonoscopies only. Gastronet is granted a waiver from the ethics committee of South-East Norway to which this national register is affiliated.

Reporting colonoscopies to Gastronet is based on two paper forms - one colonoscopy form to be filled in by the endoscopist or nurse immediately after the procedure and a patient-reported experience measures (PREM) form to be filled in by the patient on the day after the examination (English translation in the supplement). The Norwegian Directorate of Health has permitted hospitals to submit colonoscopy forms to Gastronet without patients' consent, but the patients' PREM form serves as written consent to keep patient identification for register linkage studies. This access to colonoscopy reports without consent allowed us to study selection bias in relation to consent (authorization bias). In the current study, patients who had their colonoscopy reported to Gastronet and returned the PREM form are referred to as the "consent" group, and the "no-consent" group comprised patients with a colonoscopy report to Gastronet who did not return the form.

In Norway, it is compulsory for public hospitals to report all clinical activity to the Norwegian National Patient Register (NPR). Non-reported procedures are not reimbursed. Thus, completeness of the NPR is considered to be $100 \%$. NPR does not include quality variables, but can be used to estimate completeness (coverage) of medical quality registers. Completeness can be assessed per hospital/endoscopy center, but not per endoscopist because the performing endoscopist is not reported to NPR.

In this study, Gastronet completeness was defined as the proportion of NPR-registered outpatient colonoscopies reported to Gastronet from January to December 2015. Hospitals reporting at least 100 outpatient colonoscopies in this 1-year period were included. A cut-off of 100 colonoscopies to receive hospital-specific results was arbitrarily chosen by participating centers in Gastronet. Two endoscopy centers were excluded, reporting 13 and 66 colonoscopies, respectively. The hospitals included were categorized into four groups according to observed completeness, less than $50 \%, 50 \%$ to $69 \%$, $70 \%$ to $89 \%$ and $90 \%$ to $100 \%$, respectively. These categories were chosen based on relevance to published data from quality registers [2, 6] and our focus on few events (AEs) requiring high numbers. Patient and colonoscopy characteristics and results were described for each hospital completeness category, including time spent per colonoscopy and number of AEs. Information on AEs was obtained from the colonoscopy forms and by interpretation of negative (critical) free-texts provided by the patients in the PREM form as described in a recent publication [7]. Briefly, severe AEs were defined as events requiring admission to hospital and/or some intervention beyond what could be done during the current colonoscopy. We also included cases with post-colonoscopy pain when this was combined with fever and poor general condition and cases with loss of consciousness related to the colonoscopy itself or the bowelpreparation procedure. Patients' free-text comments in the PREM form were characterized as positive or negative by consensus of three secretaries in Gastronet. All negative free-text comments were then scrutinized by one of the authors $(\mathrm{GH})$ according to whether the text expressed possible

AEs or not and events were further evaluated as severe or not severe AEs independently by $\mathrm{GH}$ and $\mathrm{TdL}$ [7].

The study was performed in two steps: First, we investigated whether reporting of AEs was associated with low completeness (coverage) and whether low completeness was associated with procedure time (duration). All hospitals reporting $>100$ colonoscopies were included in this analysis. Second, we analyzed data from hospitals with near complete data ( $\geq 90 \%$ completeness) to investigate whether procedure time was associated with frequency of AEs. In this sub-cohort, cut-offs for progressively increasing procedure-times were set to cover up to $50 \%$ of the shortest procedures ( $<20$ minutes), the next $50 \%$ to $69 \%$ (20- 25 minutes), $70 \%$ to $89 \%$ (26-41 minutes) and the last $10 \%$ (90\% to $100 \%$ ) with the longest procedure times ( $\geq 41$ minutes, Supplementary Table 1 ). Our hypothesis was that time-squeeze leads to low completeness in some centers. Then, if procedure time is an independent risk factor for AEs, centers with low completeness due to time constraints may have greater underreporting of AEs than centers with high completeness.

\section{Statistics}

Continuous, normally distributed data were analyzed with the Student's $t$-test and chi squared statistics were applied for categorical variables. One-way analysis of variance (ANOVA) was 
used for repeated measures. In the analysis of procedure-timedependent AEs within hospitals with $\geq 90 \%$ reporting completeness, univariable and multivariable logistic regression analyses were performed for AEs with the following co-variables: gender, age, cecum intubation failure, severe pain, type of colonoscopy (diagnostic/therapeutic). Statistical significance was defined as $P<0.05$ using two-sided tests. The statistical package IBM SPSS 19.0 was used.

\section{Results}

A total of 22,364 colonoscopies were performed during the study period according to the Norwegian patient register, of which 15,855 (71\%) were reported to Gastronet (> Fig.1). Eight of 20 hospitals had $\geq 90 \%$ completeness ( $\triangleright$ Table 1 ). The PREM questionnaire was returned by 11,079 patients (50\%). In addition, 402 PREM forms were received without accompanying colonoscopy forms and not included in the analyses. One $(0.2 \%)$ out of these 402 cases was registered with an AE which was abdominal pain for 3 days with no further information.

\section{Authorization bias}

Patients in the consent group were older and more often female ( $\triangleright$ Table 2). Cecal intubation failure was more frequent in colonoscopies with no consent (5.7\%) compared to colonoscopies with consent (3.5\%), $P<0.001$. Use of sedoanalgesia was more frequent in the no-consent group ( $\triangleright$ Table 2 ). The rate of AEs reported in the colonoscopy form were similar (1.0\%) in both groups. When the AEs from the PREM form were included in the analyses (free-text comments indicating an $A E$, only available in the consent group), there were 189 AEs (1.7\%) in the consent group and $50(1.0 \%)$ in the no-consent group, $P<$ 0.001 .

\section{Reporting completeness and time-dependent reporting bias}

Hospitals with low reporting completeness had longer colonoscopy procedure times and fewer AEs compared to hospitals with high completeness ( $>$ Table $\mathbf{3}, \triangleright$ Fig. 2a). Other variables like patient age, type of colonoscopy (diagnostic or therapeutic) and frequency of returned PREM forms did not show a clear, progressive completeness-dependent pattern ( $\downarrow$ Table 3 ). In particular, PREM-forms (the source of many AE registrations; - Table 2) were returned to Gastronet equally often (72\%) from patients in the highest and lowest completeness categories of hospitals ( $\triangleright$ Table 3 ).

\section{Time-squeeze dependent reporting bias}

To explore the effect of procedure time on AEs, we used data from hospitals with $\geq 90 \%$ completeness ( $>$ Fig. 2 b, Supplementary Table 1). There was very little variation in percentage of PREM-forms received between the four procedure-time groups consisting of the $50 \%$ shortest procedures, the $50 \%$ to $69 \%$ and $70 \%$ to $89 \%$ succeeding and the $90 \%$ to $100 \%$ with the longest procedures (71\%, 73\%, 72\% and 76\% PREM completeness, respectively) ( $\triangle$ Table 4$)$. This was shown both for combined diagnostic and therapeutic colonoscopies ( $\triangleright$ Table 4 )
Colonoscopies (CS) registered in the National Patient Register (NPR) from 20 hospitals Jan. - Dec 2015. $N=22,364$

$\checkmark$

CS reported to the National Quality Assurance Register Gastronet. N = 15,855 (71\%)

6,509 CS not reported to Gastronet, including 402 with PREM only

\begin{tabular}{|c|c|}
\hline \multicolumn{2}{|l|}{$\downarrow$} \\
\hline \multicolumn{2}{|c|}{$\begin{array}{l}\text { Observational study on consent-dependent } \\
\text { selection of reported CS. }\end{array}$} \\
\hline Consent: & $N=11,079 \mathrm{CS}$ \\
\hline No consent: & $\mathrm{N}=4,776 \mathrm{CS}$ \\
\hline Total: & $N=15,855 C S$ \\
\hline
\end{tabular}

Observational study on selection in relation to variations in hospital reporting of CS.

< $50 \%$ Gastronet coverage: $\quad \mathrm{N}=885 \mathrm{CS}$

$50-69 \%$ Gastronet coverage: $N=2,888 \mathrm{CS}$

70 - 89 \% Gastronet coverage: $N=4,266$ CS

> 90 \% Gastronet coverage: $\quad \mathrm{N}=7,816 \mathrm{CS}$

Total:

$\mathrm{N}=15,855 \mathrm{CS}$

> 90 \% Gastronet completeness: N = 7,816 CS

607 CS not recorded time spent on each examination

Study on procedure-time dependent of adverse events.
$<20$ min $\quad \mathrm{N}=3557 \mathrm{CS}$
$20-25 \mathrm{~min} N=1501 \mathrm{CS}$
$26-41 \mathrm{~min} N=1412 \mathrm{CS}$
$>41 \mathrm{~min} \quad \mathrm{~N}=739 \mathrm{CS}$
Total: $\quad \mathrm{N}=7209 \mathrm{CS}$

- Fig. 1 Flowchart showing sub-study distribution of 22,364 colonoscopies performed in 20 hospitals January to December 2015.

and separately for diagnostic colonoscopies only (data not shown).

Cecum intubation failure was more frequent in the groups with long compared to short procedure time ( $\triangleright$ Table 4 ). The same applied to on-site registered AEs reported in the colonoscopy form - increasing further when adding patient-reported events to provide "total AEs" ( $>$ Table 4 ).

In the hospital group with $>90 \%$ completeness, mean total time spent on colonoscopies with "on-site" registration of AEs was 31.3 minutes ( $95 \% \mathrm{Cl}: 26.6-36.0)$. This was similar to colonoscopies with events emerging clinically after the colonoscopy and reported only by the patients $(31.3$ minutes [ $95 \% \mathrm{Cl}$ : $25.3-37.3])$ while mean total time was shorter in colonoscopies with no AE 24.6 minutes ( $95 \% \mathrm{Cl} 23.2-23.8$ ) 
- Table 1 Categorization of hospital reporting completeness (groups 1 -4) expressed as the ratio of colonoscopies in the National Patient Register (NPR) that are also reported to Gastronet.

\begin{tabular}{|c|c|c|c|c|c|}
\hline Hospital & $\begin{array}{l}\text { Group 1, } \\
<50 \% \\
\text { completeness }\end{array}$ & $\begin{array}{l}\text { Group 2, } \\
50-69 \% \\
\text { completeness }\end{array}$ & $\begin{array}{l}\text { Group 3, } \\
70-89 \% \\
\text { completeness }\end{array}$ & $\begin{array}{l}\text { Group 4, } \\
\geq 90 \% \\
\text { completeness }\end{array}$ & Total \\
\hline Skien & & & $1216 / 1550(79)$ & & \\
\hline Tønsberg + Larvik & & $1694 / 3023(56)$ & & & \\
\hline Kristiansand & & & & $1552 / 1649(94)$ & \\
\hline Arendal & & & & $1092 / 1199(91)$ & \\
\hline Notodden & & & $587 / 801(73)$ & & \\
\hline Flekkefjord & & & $216 / 278(78)$ & & \\
\hline Fredrikstad & & & & $1114 / 1149(97)$ & \\
\hline Kongsberg & & & & 475/481 (99) & \\
\hline Moss & & & & $668 / 701$ (95) & \\
\hline Stavanger & & $1194 / 2236(53)$ & & & \\
\hline Kragerø & & & & $1224 / 1274(96)$ & \\
\hline Bærum & & & $1336 / 1560(86)$ & & \\
\hline Molde & & & & 938/932(101) & \\
\hline Volda & $245 / 614(40)$ & & & & \\
\hline Diakonhjemmet & $324 / 1174(28)$ & & & & \\
\hline Kristiansund & & & & $753 / 730(103)$ & \\
\hline Drammen & $188 / 1440(13)$ & & & & \\
\hline Harstad & & & $552 / 673(82)$ & & \\
\hline Namsos & $128 / 421(30)$ & & & & \\
\hline Stord & & & $359 / 479(75)$ & & \\
\hline Total & $885 / 3649(24)$ & $2888 / 5259(55)$ & $4266 / 5341(80)$ & $7816 / 8115(96)$ & $15855 / 22364(71)$ \\
\hline
\end{tabular}

Multivariable logistic regression analysis showed that procedure time was the only independent risk factor for AEs after adjusting for gender, age, cecum intubation failure, patientreported pain and whether polypectomy was performed ( $\triangleright$ Table 5).

\section{Discussion}

Safety in health care has been defined as "freedom from potentially preventable complications, iatrogenic events, accidental injury, or illness resulting from the process of care," [8-9] i.e. freedom from AEs.

AEs after colonoscopy are underreported $[7,10]$ and patient involvement has been recommended to capture all AEs, particularly late events presenting after the patient has left the endoscopy premises [10]. Also by nature of infrequent occurrence and a wide range of subjective severity, reporting of AEs may be particularly prone to underreporting and selection bias. This is paralleled in industry and fault detection measures where coverage over $90 \%$ usually shows better fault detection than random sample testing $[4,11]$.
Dependency on patients' consent is one important source of selection bias named "authorization bias" [12-13]. Authorization bias was apparent in this study with a higher cecal intubation failure rate in colonoscopies not accompanied by a PREM (consent) form (5.7\% intubation failure compared to $3.5 \%$ in the group with consent). The no-consent group was also more often subjected to sedoanalgesia, suggesting more difficult procedures as on-demand medication is the standard in these centers. Challenging procedures may thus divert attention from handing out the PREM/consent form to the patient who would then more easily evade consent-dependent registration in Gastronet. This is unfortunate because challenging colonoscopies may carry a particularly high risk of AEs. Thus, consentdependency may give a false impression of no need for quality improvement. This is not in the interest of patients [14]. Interestingly, even ethicists have challenged the need for consent when the issue is purely non-interventional observation through a QA register to improve services [15].

This study also showed that hospitals with low frequency of reporting colonoscopies to Gastronet were registered with longer mean procedure times than hospitals with high report- 
- Table 2 Patient and endoscopy characteristics for 15,855 colonoscopies reported with and without patient reply form (consent) received at the Gastronet secretariat (\%).

\begin{tabular}{|c|c|c|c|}
\hline & $\begin{array}{l}\text { Consent group } \\
\text { (colonoscopy and PREM form) }(n=11079)\end{array}$ & $\begin{array}{l}\text { No-consent group } \\
\text { (colonoscopy form only) }(n=4776)\end{array}$ & $P$ value \\
\hline \multicolumn{4}{|l|}{ Sex } \\
\hline - Men & $5047(46)$ & $2307(48)$ & \multirow[t]{3}{*}{$<0.001$} \\
\hline - Women & $6022(54)$ & $2445(51)$ & \\
\hline - Not stated & $10(0.1)$ & $24(0.5)$ & \\
\hline Age (mean yrs $[95 \% \mathrm{Cl}]$ ) & $62.7(62.4-62.9)$ & $53.9(53.4-54.4)$ & $<0.001$ \\
\hline \multicolumn{4}{|l|}{ Type of colonoscopy } \\
\hline - Diagnostic & $5593(51)$ & $2525(53)$ & \multirow[t]{3}{*}{$<0.001$} \\
\hline - Therapeutic ${ }^{1}$ & $1629(15)$ & $511(11)$ & \\
\hline - Not stated & $3857(35)$ & $1740(36)$ & \\
\hline Total exam. time $(\min )($ mean $[95 \% \mathrm{Cl}])$ & $24.9(24.7-25.2)$ & $24.0(23.6-24.4)$ & $<0.001$ \\
\hline Total time not stated & $847(7.6)$ & $489(10)$ & $<0.001$ \\
\hline Sedoanalgesia & $3844(35)$ & $1873(39)$ & $<0.001$ \\
\hline \multicolumn{4}{|l|}{ Cecal intubation status } \\
\hline - Cecum reached & $9887(89)$ & $4077(85)$ & \multirow[t]{4}{*}{$<0.001$} \\
\hline - Intubation failure & $389(3.5)$ & $271(5.7)$ & \\
\hline - Cecal intubation not intended & $93(0.8)$ & $65(1.4)$ & \\
\hline - Intubation status not stated & $710(6.4)$ & $363(7.6)$ & \\
\hline \multicolumn{4}{|l|}{ Adverse events (total) } \\
\hline - Reported in colonoscopy form & $113(1.0)$ & $50(1.0)$ & \\
\hline - Reported in PREM form only & $76(0.7)$ & $0^{2}$ & \\
\hline - Total number of adverse events & $189(1.7)$ & $50(1.0)$ & $<0.001$ \\
\hline \multicolumn{4}{|c|}{$\begin{array}{l}\text { PREM, Patient-Reported Experience Measures } \\
{ }^{1} \text { A colonoscopy including a therapeutic procedure (e. g. polypectomy) } \\
{ }^{2} \text { No patients' forms in this group, hence no statistics }\end{array}$} \\
\hline
\end{tabular}

ing completeness. This provided support to the hypothesis that time may indeed restrict reporting to quality registers, as claimed by doctors not reporting. We also found that the frequency of reported $\mathrm{AE}$ was reduced as the reporting completeness dropped ( $>$ Fig. $2 a$ ). Thus, AE reports are not linear functions of completeness with equal percentages irrespective of degrees of completeness.

Pursuing the squeeze-time hypothesis on data from the subgroup of hospitals with $90 \%$ to $100 \%$ reporting completeness, we observed a pattern of AE frequencies ( $>$ Fig. 2 c) very similar to hospitals with less degrees of completeness ( $\nabla$ Fig. 2a) only with higher frequencies of AEs ( $>$ Fig.3). This suggests that the frequency of AEs may be higher in colonoscopies not reported, irrespective of coverage. Among the 402 PREMs not accompanied by a colonoscopy report, there was, however, only one report suggesting an AE. Particularly on-site complications may be underreported in this group lacking information from colonoscopy reports.
Because the frequencies of AEs may be driven disproportionally by changes in reporting completeness and colonoscopy procedure time, it is difficult to define cut-off values for adequate completeness of quality assurance registers. Thus, selection bias for clinically important endpoints may be a problem whether completeness is $50 \%, 70 \%$ or even $90 \%$ and we have gained only limited knowledge as to the reasons for this (Supplementary Table 2). There was no difference between hospitals with low and high reporting completeness regarding cecal intubation rates, but a non-significant trend for higher detection rates for polyps $\geq 5 \mathrm{~mm}$ in hospitals with low registry input (data not shown).

There are several weaknesses and uncertainties to this study which mainly emerge from its sole purpose: trying to disclose what is happening in procedures not being reported to quality registers. This requires a number of assumptions which may or may not be supported by observational data. In disclosing the authorization bias, we were fortunate to have information on procedures reported both with and without consent (authoriza- 
- Table 3 Demographics and colonoscopy characteristics according to Gastronet completeness groups of hospitals.

\begin{tabular}{|c|c|c|c|c|c|}
\hline & \multicolumn{4}{|c|}{ Gastronet observed completeness } & \multirow[b]{2}{*}{$P$ value } \\
\hline & $\begin{array}{l}\text { Group } 1 \text {, } \\
<50 \% \text { completeness } \\
(n=885)\end{array}$ & $\begin{array}{l}\text { Group } 2 \text {, } \\
50 \%-69 \% \\
\text { completeness } \\
(n=2888)\end{array}$ & $\begin{array}{l}\text { Group } 3 \text {, } \\
70 \%-89 \% \\
\text { completeness } \\
(n=4266)\end{array}$ & $\begin{array}{l}\text { Group } 4 \text {, } \\
>90 \% \\
\text { Completeness } \\
(n=7816)\end{array}$ & \\
\hline \multicolumn{6}{|l|}{ Sex } \\
\hline - Men & $396(45)$ & $1307(45)$ & $1982(47)$ & $3669(47)$ & \multirow[t]{3}{*}{0.21} \\
\hline - Women & $488(55)$ & $1573(55)$ & $2280(53)$ & $4126(53)$ & \\
\hline - Not stated & $1(0.1)$ & $8(0.3)$ & $4(0.1)$ & $21(0.3)$ & \\
\hline $\begin{array}{l}\text { Age (yrs) } \\
\text { (mean }[95 \% \mathrm{Cl}] \text { ) }\end{array}$ & $\begin{array}{l}59.4 \\
(58.3-60.4)\end{array}$ & $\begin{array}{l}58.9 \\
(58.3-59.5)\end{array}$ & $\begin{array}{l}59.8 \\
(59.3-60.3)\end{array}$ & $\begin{array}{l}60.7 \\
(60.4-61.0)\end{array}$ & $<0.001$ \\
\hline \multicolumn{6}{|l|}{ Type of colonoscopy } \\
\hline - Diagnostic & $400(45)$ & $1581(55)$ & $2005(47)$ & $4132(53)$ & \multirow[t]{3}{*}{$<0.001$} \\
\hline - Therapeutic ${ }^{1}$ & $165(19)$ & $317(11)$ & $413(9.7)$ & $1245(16)$ & \\
\hline - Not stated & $320(36)$ & $990(34)$ & $1848(43)$ & $2439(31)$ & \\
\hline Cecum intub.failure & $23(2.6)$ & $104(3.6)$ & $145(3.4)$ & $255(3.3)$ & 0.51 \\
\hline Polyp detection ${ }^{2}$ & $248(28)$ & $703(24)$ & $1122(26)$ & $1945(25)$ & 0.05 \\
\hline $\begin{array}{l}\text { Total exam. time (min) } \\
\text { (mean }[95 \% \mathrm{Cl}] \text { ) }\end{array}$ & $\begin{array}{l}28.1 \\
(27.3-28.9) \\
(n=834)\end{array}$ & $\begin{array}{l}25.9 \\
(25.4-26.3) \\
(n=2701)\end{array}$ & $\begin{array}{l}25.1 \\
(24.7-25.5) \\
(n=3775)\end{array}$ & $\begin{array}{l}23.6 \\
(23.3-23.9) \\
(n=7209)^{3}\end{array}$ & $<0.001^{4}$ \\
\hline \multicolumn{6}{|l|}{ Adverse events } \\
\hline - Severe adverse event & $3(0.3)$ & $2(0.1)$ & $12(0.3)$ & $22(0.3)$ & \\
\hline - Other adverse event & $2(0.2)$ & $32(1.1)$ & $64(1.5)$ & $101(1.3)$ & \\
\hline - Total adverse events & $5(0.6)$ & $34(1.2)$ & $76(1.8)$ & $123(1.6)$ & 0.02 \\
\hline PREM form returned & $636(72)$ & $1926(67)$ & $2912(68)$ & $5605(72)$ & $<0.001$ \\
\hline Severe pain & $66 / 636(10)$ & $221 / 1926(12)$ & $355 / 2912(12)$ & $714 / 5605(13)$ & 0.22 \\
\hline $\begin{array}{l}\text { Negative free text, patients' } \\
\text { reply form }\end{array}$ & $20(2.3)$ & $83(2.9)$ & $132(3.1)$ & $189(2.5)$ & 0.12 \\
\hline \multicolumn{6}{|c|}{$\begin{array}{l}\text { PREM, Patient-Reported Experience Measures } \\
{ }^{1} \text { A colonoscopy including a therapeutic procedure (e. g. polypectomy). } \\
{ }^{2} \text { Detection of at least one polyp } \geq 5 \mathrm{~mm} \text { regardless of histology. } \\
{ }^{3} \text { Number used for time-dependent modelling (Table } 4 \text { ) } \\
{ }^{4} \text { One-way ANOVA }\end{array}$} \\
\hline
\end{tabular}

tion) and the analyses exposed selection bias with regard to age, cecal intubation and need for sedoanalgesia. These were, however, mere surrogates for the main outcome: AEs, data on which were not available from patients' forms in the no-consent group. This represents a weakness since 76 of 189 AEs ( $40 \%$ ) were reported only in the patient's PREM/consent form in the consent group ( $\triangleright$ Table 2 ).

Excessive time spent on each colonoscopy is a plausible explanation for failing to hand out patient reply forms and downprioritizing a task of no relevance for the current treatment of the patient. Apparently, this was not the case in this study showing little variation in patient reply form coverage ranging from $67 \%$ to $72 \%$ of reported colonoscopies in the four categories of hospitals ( $\triangleright$ Table 3 ). This does not support the down-prioritizing of tasks due to shortage of time, unless handing out the patient reply form is a staff task unrelated to the endoscopist time-squeeze, but it strengthens the comparison of AEs between hospital groups because patient reply forms contributed so strongly to registration of AEs. A prerequisite for PREM coverage is to hand out the form to the patient. If this is a task for the nurse while time-squeeze shortcuts are more prevalent for the endoscopist, then this may explain similar PREM coverage irrespective of the time-dependent grouping of hospitals in this study.

The endoscopy units' reporting completeness varied greatly between hospitals, ranging from $13 \%$ to $100 \%$ ( $\triangleright$ Table 1 ). For low-completeness hospitals, it is assumed that endoscopists have the possibility of not reporting their procedures. We do 


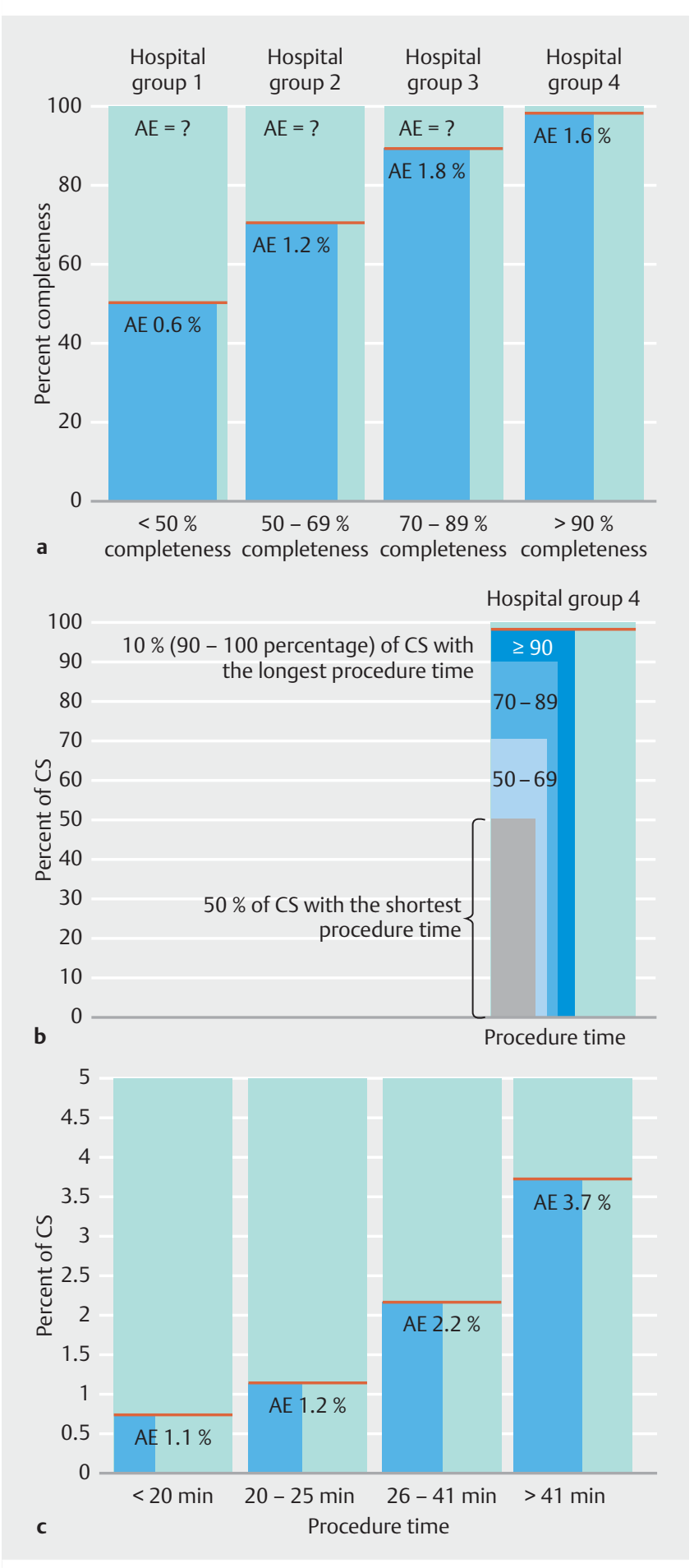

- Fig. 2 a Adverse events and colonoscopy (CS) reporting coverage. The figure shows categories of hospitals according to proportion of colonoscopies reported to Gastronet (hospital coverage groups $1-4)$ and the frequency of adverse events (AE) limited to colonoscopy reports received in Gastronet. The width of the blue columns visualize differences in mean total time spent per colonoscopy (values presented in $>$ Table 3). b This illustrates how the nearly complete dataset from hospital group 4 (90\%-100\% reporting completeness) can be used to estimate variations in frequency of adverse events dependent on a progressive time-squeeze on procedure times spent on colonoscopy (Supplementary Table 1). c This shows the four time-squeeze groups in $>$ Fig. $\mathbf{2 b}$ presented as separate columns with corresponding frequencies of adverse events. not know if this may be due to a few endoscopists with high colonoscopy activity and/or many with less activity. Also, we do not know the characteristics of endoscopists not reporting, but a frequently presented argument for not reporting has been "We do not have the time for this," in spite of less than 2 minutes being required for the endoscopist to fill in the colonoscopy form (unpublished data).

Total colonoscopy examination time as a proxy for timesqueeze may be a poor surrogate for the highly subjective sense of stressful shortage of time and a need to cut down on reporting. Stressful time-squeeze depends not only on time spent for the current colonoscopy, but also on lagging behind after the previous patient in the list. Poor organization may further contribute to competing urgent tasks needing to be addressed during and immediately after the current examination. An already stressful atmosphere may escalate when you are 10 to 15 minutes into your next 30 -minute timeslot in a very tight clinical list. These factors, not necessarily reflected in the time spent on the current patient, may contribute additionally towards underreporting of sub-performance and AEs.

The main driving force for public health services is to provide equal access and quality of services irrespective of socioeconomic status and place of living. In this study, all endoscopy centers were public hospitals. To verify a national aim of equal service provision and low risk of AEs for patients, you need a QA register with national coverage and completeness. Without this, it cannot be documented that the political aim of equality has been reached. Our study suggests that incomplete QA registers do not provide valid information on AEs.

For many registers, it will be very resource-intensive to achieve $100 \%$ completeness. Singular focus to achieve anything short of $100 \%$ completeness may still be insufficient to satisfy valid skepticism about data quality. We believe that both from a resource and data quality perspective, electronic medical records (EMRs) should be adequately structured with integrated registration of relevant quality data as part of routine medical recording [16]. These data should be automatically loaded into real-time display of quality register data [17]. Informed consent should not be a prerequisite for research on quality register data $[15,18]$ as this itself will create bias. It takes time to develop such integrated tools and overcome regulations. Meanwhile, we suggest that quality registers reporting on medical procedure performance aim to improve insight into the extent of uncertainties and possible biases in their data. Exposure of QA shortcomings may inspire extra efforts to accommodate $\mathrm{QA}$ registers as a natural, integrated part of routine EMRs. This process is long overdue.

\section{Conclusion}

In conclusion, the current study has verified authorization bias in a colonoscopy QA register and observed a procedure-timedependent bias in registration of AEs while the reasons for this time-dependency remain unknown. Data from a group of public hospitals with almost $100 \%$ reporting completeness could be used to estimate the degree of underreporting in groups of hospitals with less reporting completeness. Register data 
- Table 4 Characteristics of colonoscopies performed with successive variations in procedure times. Data are based on total time spent per colonoscopy $(n=7209)$ in the group of hospitals with $\geq 90 \%$ completeness (procedure times are missing for 607 out of 7816 colonoscopies in this group of hospitals).

\begin{tabular}{|c|c|c|c|c|c|c|}
\hline & \multicolumn{4}{|c|}{ Procedure time-dependent categorization of colonoscopies in hospital group 4} & \multirow[b]{2}{*}{ Total } & \multirow[b]{2}{*}{$P$ value } \\
\hline & $\begin{array}{l}\text { Group I, } \\
50 \% \text { with short- } \\
\text { est procedure } \\
\text { times }\end{array}$ & $\begin{array}{l}\text { Group II, } \\
50 \%-69 \% \\
\text { (20\% succeeding } \\
\text { procedure times) }\end{array}$ & $\begin{array}{l}\text { Group III, } \\
70 \%-89 \% \\
\text { (20\% succeeding } \\
\text { procedure times) }\end{array}$ & $\begin{array}{l}\text { Group IV, } \\
>90 \% \\
\text { (10\% with longest } \\
\text { procedure times) }\end{array}$ & & \\
\hline Procedure time range (min.) & $<20$ & $20-25$ & $26-41$ & $>41$ & & \\
\hline \multicolumn{7}{|l|}{ Colonoscopy form data } \\
\hline Colonoscopy reports & 3557 & 1501 & 1412 & 739 & 7209 & \\
\hline Cecum intubation failure (\%) & $54(1.5)$ & $24(1.6)$ & $47(3.3)$ & $27(3.7)$ & $152(2.1)$ & $<0.001$ \\
\hline On-site adverse events(\%) & $29(0.8)$ & $12(0.8)$ & $20(1.4)$ & $19(2.6)$ & $80(1.1)$ & $<0.001$ \\
\hline Total adverse events $(\%)^{1}$ & $38(1.1)$ & $18(1.2)$ & $31(2.2)$ & $27(3.7)$ & $114(1.6)$ & $<0.001$ \\
\hline \multicolumn{7}{|l|}{ PREM form data } \\
\hline PREM forms(\%) & $2541(71)$ & $1101(73)$ & $1017(72)$ & $564(76)$ & $5223(73)$ & 0.04 \\
\hline Severe pain & $202(7.9)$ & $155(14.1)$ & $173(17.0)$ & $101(17.9)$ & $631(12.1)$ & $<0.001$ \\
\hline Negative comments(\%) & $67(2.6)$ & $29(2.6)$ & $53(5.2)$ & $30(5.3)$ & $179(3.4)$ & $<0.001$ \\
\hline
\end{tabular}
comments in patients' reply form.

- Table 5 Odds ratio (OR) for adverse events in a multivariable logistic regression model adjusting for gender, age, caecum intubation failure, patient reported pain, type of colonoscopy (CS) and modelled registration completeness categories.

\begin{tabular}{|c|c|c|c|c|c|}
\hline & \multirow[b]{2}{*}{ No. of CS } & \multicolumn{2}{|l|}{ Unadjusted OR } & \multicolumn{2}{|l|}{ Adjusted OR } \\
\hline & & Mean (95\% Cl) & $P$-value & Mean (95\% Cl) & $P$ value \\
\hline \multicolumn{6}{|l|}{ Gender $^{1}$} \\
\hline Men & 3408 & 1.0 (reference) & & 1.0 (reference) & \\
\hline Women & 3780 & $1.0(0.7-1.5)$ & 0.91 & $0.6(0.4-1.0)$ & 0.07 \\
\hline $\mathrm{Age}^{1}$ & 7186 & $1.0(1.0-1.0)$ & 0.31 & $1.0(1.0-1.0)$ & 0.13 \\
\hline \multicolumn{6}{|l|}{ Complete examination } \\
\hline Cecum or aim reached & 7057 & 1.0 (reference) & & 1.0 (reference) & \\
\hline Cecum intubation failure & 152 & $2.2(0.9-5.4)$ & 0.10 & $3.0(1.0-8.9)$ & 0.46 \\
\hline \multicolumn{6}{|l|}{ Pain $^{2}$} \\
\hline None, slight/moderate pain & 4592 & 1.0 (reference) & & 1.0 (reference) & \\
\hline Severe pain & 631 & $1.8(1.1-3.0)$ & 0.02 & $1.8(1.0-3.3)$ & 0.65 \\
\hline \multicolumn{6}{|l|}{ Type of colonoscopy ${ }^{1}$} \\
\hline Diagnostic & 3867 & 1.0 (reference) & & 1.0 (reference) & \\
\hline Therapeutic & 1198 & $1.8(1.1-2.8)$ & 0.01 & $1.3(0.8-2.3)$ & 0.31 \\
\hline \multicolumn{6}{|l|}{ Percentage completeness } \\
\hline$<50 \%$ & 3557 & 1.0 (reference) & & 1.0 (reference) & \\
\hline $50 \%-69 \%$ & 1501 & $1.1(0.6-2.0)$ & 0.69 & $0.8(0.4-1.9)$ & 0.64 \\
\hline $70 \%-89 \%$ & 1412 & $2.1(1.3-3.4)$ & 0.003 & $2.6(1.4-4.8)$ & 0.003 \\
\hline$\geq 90 \%$ & 739 & $3.5(2.1-5.8)$ & $<0.001$ & $3.6(1.8-7.1)$ & $<0.001$ \\
\hline
\end{tabular}




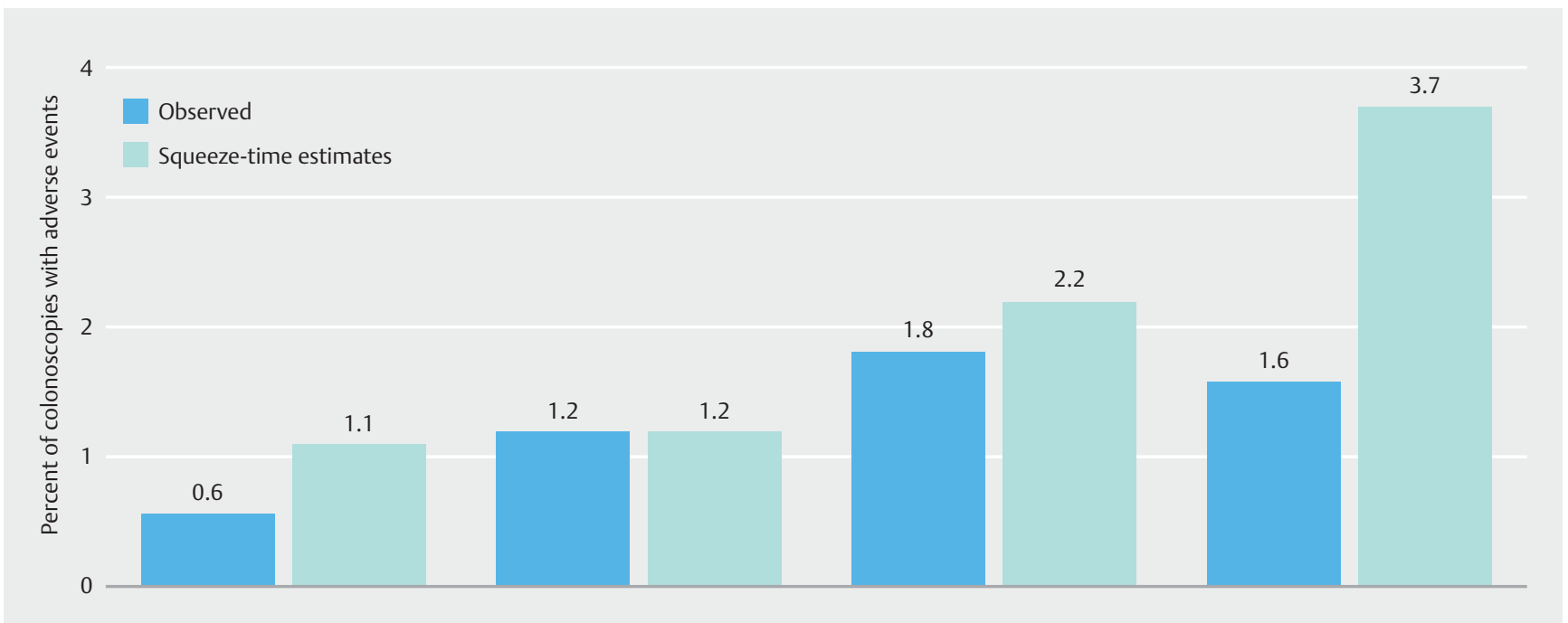

- Fig. 3 Visualization of complications as observed in $>$ Fig. 2a (dark blue columns) and when applying progressive time-limits to procedure times in the dataset from hospital group 4 in $\mathbf{F i g . 2 c}$ (pale blue columns).

should be used to estimate type and degrees of bias and expose challenges in obtaining valid data for QA when legislation and reporting technologies do not facilitate $100 \%$ completeness.

\section{Acknowlegements}

This study would not have been possible without the dedicated work of doctors, nurses and staff in participating endoscopy centers and the Gastronet secretariat. The Gastronet quality register receives funding from the South-East Norway Regional Health Board. The funders have played no role in the running of Gastronet or Gastronet research activities.

\section{Competing interests}

Dr. Hoff received payment from AMGEN Norway in 2017 for giving a lecture in 2017 .

\section{References}

[1] Black N. To do the service no harm: the dangers of quality assessment. J Health Services Res Policy 2015; 20: 65-66

[2] Rahr-Wagner L, Thillemann TM, Lind MC et al. Validation of 14,500 operated knees registered in the Danish Knee Ligament Reconstruction Register: registration completeness and validity of key variables. Clin Epidemiol 2013; 5: 219-228

[3] Gundtoft PH, Varnum C, Pedersen AB et al. The Danish Hip Arthroplasty Register. Clin Epidemiol 2016; 8: 509-514

[4] Williams TW, Mercer MR, Mucha JP et al. Code coverage, what does it mean in terms of quality? Proceedings. Annual Reliability and Maintainability Symposium 2001. IEEE; 2001: 420-424

[5] van der Veer SN, de Keizer NF et al. Improving quality of care. A systematic review on how medical registries provide information feedback to health care providers. Int J Medical Inform 2010; 79: 305 - 323
[6] Appelros P, Samuelsson M, Karlsson-Tivenius S et al. A national stroke quality register: 12 years experience from a participating hospital. Eur J Neurol 2007; 14: 890 - 894

[7] Hoff G, de Lange T, Bretthauer M et al. Patient-reported adverse events after colonoscopy in Norway. Endoscopy 2017; 49: 745-753

[8] Simpson KR. Measuring perinatal patient safety: review of current methods. J Obst Gyn Neonatal Nursing 2006; 35: 432-442

[9] Filker PJ, Muckey EJ, Kelner SM et al. Taking a quality assurance program from paper to electronic health records: one dental school's experience. J Dental Ed 2009; 73: 1095-1101

[10] Valori R, Sint Nicolaas J, de Jonge V. Quality assurance of endoscopy in colorectal cancer screening. Best Practi Res Clinl Gastroenterol 2010; 24: $451-464$

[11] Hutchins M, Foster H, Gordia T et al. Experiments on the effectiveness of dataflow- and controlflow-based test adequacy criteria. IEEE 1994: $191-200$

[12] Tu JV, Willison DJ, Silver FL et al. Investigators in the Registry of the Canadian Stroke N: Impracticability of informed consent in the Registry of the Canadian Stroke Network. N Engl J Med 2004; 350: 1414 1421

[13] Jacobsen S], Xia Z, Campion ME et al. Potential effect of authorization bias on medical record research. Mayo Clin Proc 1999; 74: 330-338

[14] Al-Shahi R, Warlow C. Using patient-identifiable data for observational research and audit. BMJ 2000; 321: 1031-1032

[15] Miller FG. Research on medical records without informed consent. J Law Med Ethics 2008; 36: 560 - 566

[16] Hoff G. Quality assurance in gastroenterology: QA in research, and research in QA. Best Pract Research Clin Gastroenterol 2011; 25: $427-434$

[17] Hoff G, Ottestad PM, Skaflotten SR et al. Quality assurance as an integrated part of the electronic medical record - a prototype applied for colonoscopy. Scand J Gastroenterol 2009; 44: 1259-1265

[18] Kho ME, Duffett M, Willison DJ et al. Written informed consent and selection bias in observational studies using medical records: systematic review. BMJ 2009; 338: b866 